\title{
EFFECT OF EXERCISE ON VENTILATORY FUNCTION IN WELDERS
}

\author{
By \\ El Batanony M.M.*, Salem E.Y. ** and El-Nahas H. E. *** \\ From \\ *Department of Industrial Medicine and Occupational Diseases, Faculty of Medicine, Cairo University, \\ **Fitness and Rehabilitation unit, Cairo University and *** Cairo University Hospitals.
}

\begin{abstract}
:
Objective: This study was conducted to clarify the effect of different types of exercises in improving ventilatory functions in welders. Methods: Sixty male welders, age ranged between 20-30 years, have been selected from Abu Al Yazid welding exhaust factory at $6^{\text {th }}$ of October industrial area. Data of each case were collected from the medical examination and Spirometric results to measure forced vital capacity (FVC), forced expiratory volume in the first second (FEV1) and maximum voluntary ventilation (MMV). Before the period of training the workers were classified randomly into three groups. First group was trained by arm exercise connected with breathing. Second group was trained by incentive spirometer. Third group was trained by both arm exercise and incentive spirometer. The ventilatory function test was performed to each subject pre and after two months of training to mark out the values of FVC, FEV1, and MVV. Results: Results showed that breathing exercise programs improve ventilatory functions (FVC, FEV1, MVV) after two months of training. Conclusion: The study supports the importance of arm exercise connected with breathing and incentive spirometer as a method of breathing exercise in improving the ventilatory functions in welders.
\end{abstract}

Key words: Welding, incentive spirometer, arm exercise with breathing, ventilatory function test. 


\section{Introduction}

It is estimated that more than one million workers worldwide perform some type of welding a part of their work duties ${ }^{(1)}$. There are many respiratory problems that may be associated with welding that vary from acute responses such as that seen in metal fume fever usually associated with zinc oxide inhalation to less common cases of hypersensitivity pneumonitis and chronic sequelae such as welding related pneumoconiosis $(2,3,4)$.

Several studies have documented a high prevalence of symptoms of chronic bronchitis and other work related respiratory symptoms in current welders. Also workers with chronic bronchitis had reduced peak expiratory flow(PEF) and forced expiratory volume in first second/forced vital capacity (FEV1/FVC) $^{(5,6)}$, and FEV1 ${ }^{(7)}$. In the early interstitial involvement of the lung, pulmonary function tests may provide the only evidence of disease and thus the only indication for evaluation ${ }^{(8,9,10)}$.

Breathing exercises are the most potent factor capable of increasing the pulmonary ventilation and improving mobilization of the chest wall, drainage of tracheo-bronchial secretions, promote relaxations as well as to maintain and improve chest wall mobility and to regain the most efficient breathing pattern ${ }^{(11)}$.
There are many types of breathing exercise and the exercise connected with breathing is more beneficial to improve ventilation, oxygenation, increase the number of muscles used and increase chest mobility ${ }^{(12)}$. Application of deep breathing exercises revealed a significant increase in vital capacity(VC), forced expiratory volume at first second (FEV1), peak expiratory flow (PEF), and maximal voluntary ventilation (MVV) ${ }^{(13)}$. The aim of this study was a comparison between exercise connected with breathing, incentive spirometer and incentive spirometer combined with exercise connected with breathing on the improvement of ventilatory functions on welders.

\section{Subjects and methods}

Sixty male welders, age ranged between 20-30 years, have been selected randomly from Abu Al Yazid welding exhaust factory at $6^{\text {th }}$ of October industrial area using metal arc welding. The workers were chosen to be exposed to welding fumes for at least 5 years, they were non smokers and without any previous pulmonary or cardiovascular disorders through clinical examination. Subject were classified randomly into three groups: Group (1): 20 workers trained by arm exercise connected with breathing, group (2): 20 workers trained by incentive spirometer and group(3): 20 workers 
trained by both arm exercises and incentive spirometer. The practical work was carried out in summer season three sessions per week for two months for all groups.

\section{Procedures}

\section{1)-Evaluation:}

Workers were assessed to exclude patients with any pulmonary or cardiovascular disease. The assessment included full history taking and clinical examination. Ventilatory function tests (Spirometry) were done in order to measure forced vital capacity (FVC), forced expiratory volume at the end of the first second (FEV1), maximum voluntary ventilation (MVV).

\section{2)-Training programs:}

Group (1): (arm exercise connected with deep breathing).

Each worker performed the following steps within 40 minutes

Warming up phase: exercises done for 5 minutes in the form of forward lean standing with swinging upper limbs.

Breathing exercises phase: via deep breathing with abduction of upper limbs, then expire air with adduction of upper limbs five minutes for exercise and one minute for rest and repeat again for thirty minutes.
Cool down phase: relaxation position to ensure maximum relaxation of all body and returning to his resting state. Relaxed backward sitting for 5 minutes.

Group (2): (incentive spirometer).

Workers were instructed on how to use the incentive spirometer. Each subject followed these instructions:

1-The worker must be in comfortable sitting position.

2-The worker holds the spirometer by one hand and the tube mouth piece by the other hand.

3- The worker takes three to four slow, easy breaths.

4- The worker maximally exhales with the fourth breath.

5- Then the worker places the incentive spirometer and holds inspiration for several seconds allowing hinging the balls at higher position then rest for 60 seconds.

6- The sequence is repeated for 30 minutes, 3 times/week for 2 months.

Group (3): (incentive spirometer and arm exercise connected with deep breathing).

In this group each subject performed the previous steps in group 1 for thirty minutes, 
15 minutes for incentive spirometer and 15 minutes for upper limb exercises connected with breathing with 5 minutes of warming up at the beginning and 5 minutes for cooling down at the end of exercise.

\section{Statistical analysis}

Data are presented as means \pm standard deviation $(\grave{\mathrm{x}} \pm \mathrm{SD})$. The within groups comparisons were done using Paired "T" test and between groups comparisons were carried out using unpaired " $\mathrm{t}$ " test. Statistical significance was assumed at a P. value of $<0.05$.

\section{Results}

The measured ventilatory functions were: forced vital capacity (FVC), forced expiratory volume in the first second (FEV1) and maximum voluntary ventilation (MVV).

Table (1) revealed that there was no statistical significant difference as regards age, weight and height between groups of the study.
Table (2) revealed that there was a highly statistically significant improvement in all variables after treatment in Group I as regards, FVC, FEV1and MVV.

Table (3) showed that there was a highly significant difference $(\mathrm{p}<0.001)$ of all variables after using incentive spirometer.

Table (4) showed that there was a highly significant improvement of all variables after treatment in Group III.

Table (5) revealed that there was no statistical significant difference of all variables as regards FVC, FEV1 and MVV between groups at the beginning of the study.

Table (6) revealed that after treatment there was highly statistical significant increase in all ventilatory functions of group II in relation to group I and in group III in relation to group I. However, as regards group III in relation to group II, there was increase in all ventilatory functions but yet with no statistical significant difference. 
Table (1) :Demographic data of group I, II, III.

\begin{tabular}{|l|c|c|c|l|}
\hline \multirow{2}{*}{ Variable } & \multicolumn{3}{|c|}{ Mean \pm SD } & \multirow{2}{*}{ P Value } \\
\cline { 2 - 4 } & GI & GII & GIII & \\
\hline \multirow{2}{*}{ Age/years } & $\begin{array}{c}25.35 \pm 3.55 \\
(23.6-30)\end{array}$ & $\begin{array}{c}25.85 \pm 3.09 \\
(21-27)\end{array}$ & $\begin{array}{c}25.100 \pm 2.99 \\
(23.7-26.4)\end{array}$ & \multirow{2}{*}{$\mathrm{P}>0.05$} \\
\hline Weight/Kg & $76.25 \pm 9.12$ & $76.30 \pm 8.29$ & $\begin{array}{r}76.05 \pm 7.73 \\
(72.4-79.6)\end{array}$ & \multirow{2}{*}{$\mathrm{p}>0.05$} \\
\hline \multirow{2}{*}{ Height/Cm } & $\begin{array}{c}(71.97-80.52) \\
(175.05 \pm 5.77\end{array}$ & $\begin{array}{c}175.35 \pm 5.9 \\
(172.5-178)\end{array}$ & $\begin{array}{c}175.2 \pm 6.38 \\
(172.2-178)\end{array}$ & \multirow{2}{*}{$\mathrm{p}>0.005$} \\
\hline
\end{tabular}

$\mathrm{Cm}$ : centimeter $\quad \mathrm{Kg}$ : kilogram

Table (2): Statistical analysis before and after arm exercises connected with breathing on ventilatory functions in group $I$.

\begin{tabular}{|l|c|c|c|c|}
\hline \multirow{2}{*}{ Ventilatory functions } & \multicolumn{2}{|c|}{ Mean \pm SD } & \multirow{2}{*}{ t value } & \multirow{2}{*}{ P- Value } \\
\cline { 2 - 3 } VC/liter & before & after & 8.886 & 0.001 \\
\hline FEV1/liter & $4.11 \pm 0.18$ & $4.23 \pm 0.14$ & 5.386 & 0.001 \\
\hline MVV/ liter/minute. & $3.07 . \pm 0.36$ & $3.35 \pm 0.29$ & 18.354 & 0.001 \\
\hline
\end{tabular}


Table (3): Statistical analysis before and after incentive spirometer use on ventilatory functions in group (II).

\begin{tabular}{|l|c|c|c|c|}
\hline \multirow{2}{*}{ Ventilatory functions } & \multicolumn{2}{|c|}{ Mean \pm SD } & \multirow{2}{*}{ t value } & P- Value \\
\cline { 2 - 3 } & Before & after & 10.146 & 0.001 \\
\hline FVC/liter & $4.11 \pm 0.12$ & $4.44 \pm 0.17$ & 9.246 & 0.001 \\
\hline FEV1/liter & $3.07 . \pm 0.39$ & $3.65 \pm 0.23$ & 12.752 & 0.001 \\
\hline MVV/ liter /minute. & $112 \pm 5.19$ & $126.2 \pm 5.54$ & \\
\hline
\end{tabular}

Table (4): Statistical analysis before and after arm exercises connected with breathing and incentive spirometer on ventilatory functions in group III:

\begin{tabular}{|l|c|c|c|c|}
\hline \multirow{2}{*}{ Ventilatory functions } & \multicolumn{2}{|c|}{ Mean \pm SD } & \multirow{2}{*}{ t value } & \multirow{2}{*}{ P- Value } \\
\cline { 2 - 3 } & Before & after & \\
\hline FVC/liter & $4.10 \pm 0.15$ & $4.48 \pm 0.20$ & 14.391 & 0.001 \\
\hline FEV1/liter & $3.07 . \pm 0.30$ & $3.67 \pm 0.25$ & 9.790 & 0.001 \\
\hline MVV/ liter/minute. & $111.95 \pm 6.8$ & $128.5 \pm 8.1$ & 17.427 & 0.001 \\
\hline
\end{tabular}




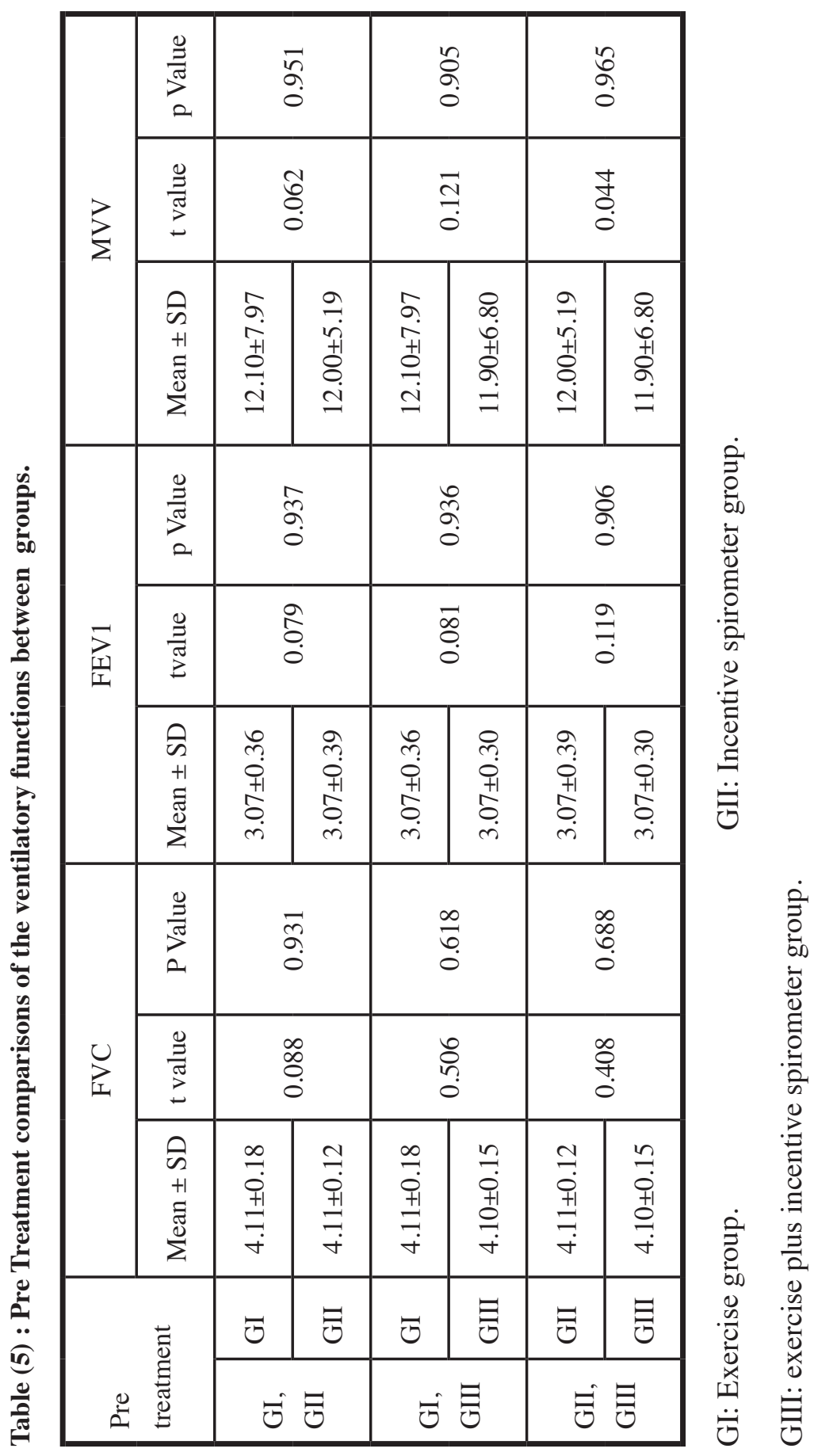


El Batanony M.M. et al.,

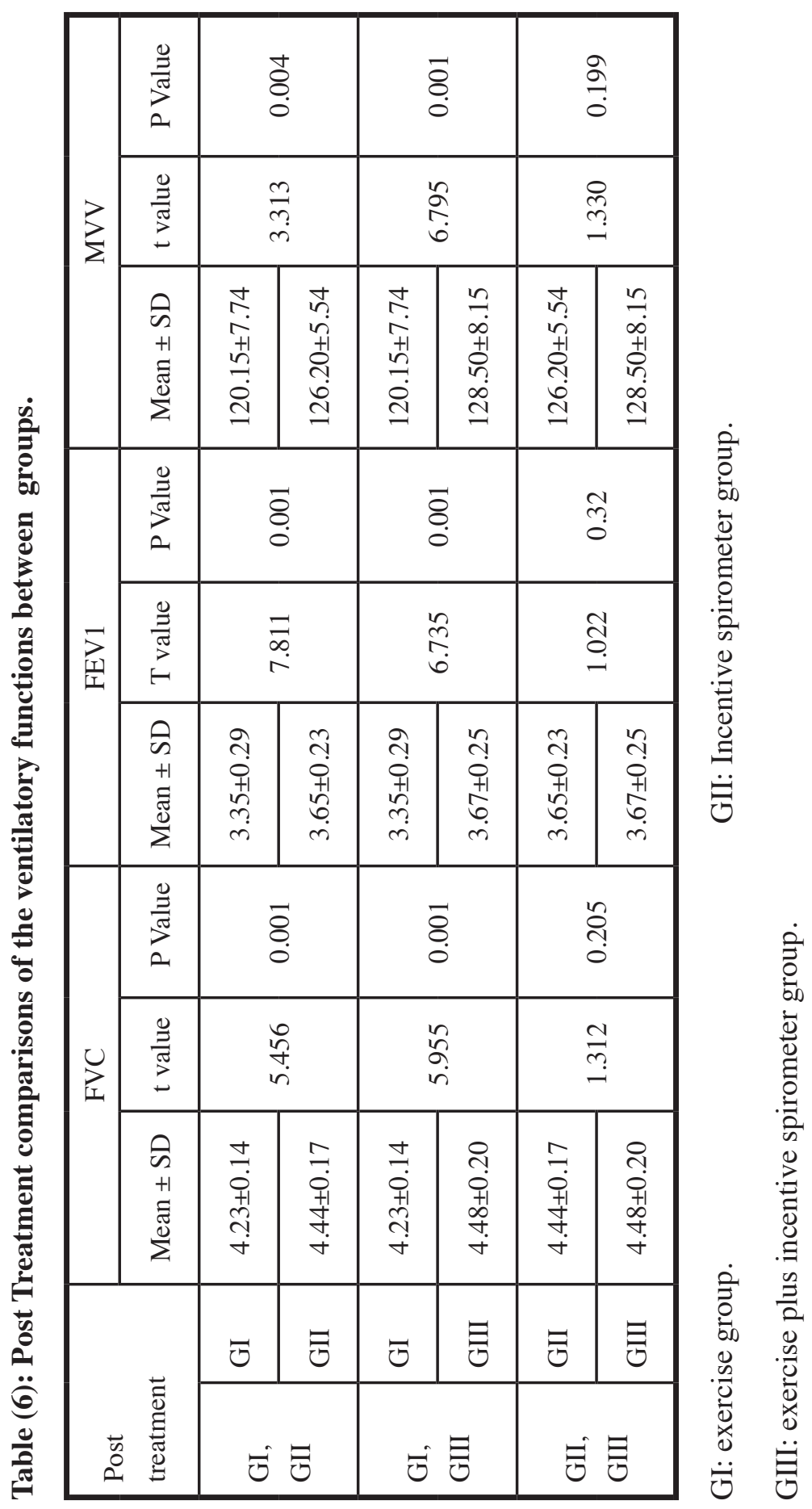




\section{Discussion}

The majority of cross sectional studies have shown a higher prevalence of ventilatory impairment in welders ${ }^{(5,14)}$. The aim of this study was to find out which of the methods, mentioned before, has the most significant effect on improving ventilatory functions. The methods are breathing exercises connected with upper limb exercises, incentive spirometry or both together.

The results of this study pre training showed a normal values of FVC, MVV, low level FEV1(about $61 \%$ of predicted), but FEV1/FVC was at low normal level about $75 \%$ of predicted. It was stated that welding is associated with a fall in FEV $1^{(6)}$. A reduction in FVC by $17.4 \%$ and $11.7 \%$, in high \& low exposed welders and $4.6 \%$ in non welding- exposed workers metal fumes, respectively ${ }^{(15)}$. Several studies revealed a significant reduction in ventilatory functions (FVC, FEV1,2,3, MVV,FVC/FEV1\%), indicating obstructive abnormities ${ }^{(16,17)}$.

After training in group (I), there was significant improvement in FVC, FEV1 and MVV with improved percentage of 2.9, 9.1 and $7.2 \%$ respectively. These results agreed with a previous study which proved that the ventilatory exercise program improves all measured pulmonary parameters (FVC,FEVI and MVV) $)^{(18)}$.
It was stated that muscular exercise increases the rate and depth of respiration and so improve FVC, the consumption of $\mathrm{O}^{2}$ and the rate of diffusion ${ }^{(19)}$.

Breathing exercise promotes a more efficient breathing pattern, improvement in ventilation and increases in $\mathrm{FVC}$, the increase in FVC post exercise might be related to the enhanced strength of respiratory muscles following training, a reduction in air trapping, improvement in lung compliance, reduced air way resistance and the process of motivation which enforces the subject to take deep inspiration and fill all air passages after training ${ }^{(20)}$.

Amawy et al 1982 showed that there was significant improvement in the FEV1 with a mean percent of change $17 \%$ after one month of physical training in the form of postural drainage with the use of mechanical vibrator, arm exercise in the form of arm swings, swimming movements and arm circles followed by breathing exercise in a form of diaphragmatic breathing and localized breathing exercise(6days/week) applied on workers in jute and hemp industry ${ }^{(21)}$.

It was mentioned that MVV is important because it reflects severity of airway obstruction as well as the patients 
respiratory reserves, muscle strength and motivation ${ }^{(22)}$. It was stated that training of respiratory muscles can significantly increase MVV as prolonged intense constant intensity exercise, reduce blood lactate concentration and improve lactate uptake by these trained muscles as fuel for their own activity ${ }^{(23)}$.

The results were supported by a previous study which measured the effect of breathing exercise (postural exercise connected with breathing) on pulmonary function in insecticides spray workers. The increase in FVC and MVV following breathing exercises was due to improvement in muscle strength and endurance, maintaining of positive pressure in the air ways by removal of excessive secretions, keeping them open and improving the efficiency of ventilation ${ }^{(24)}$. Also there was postulation that breathing exercises increase the strength and endurance of respiratory muscles. Also, the possible explanation of significant improvement of MVV following breathing exercises was due to improved muscle strength and endurance ${ }^{(25)}$.

It is known that normally, the volume and pattern of ventilation are initiated by neural output from the respiratory center in the brain stem. This output is influenced by input from carotid $\mathrm{Pao}^{2}$ and central $\mathrm{PaCo}^{2}$, [H+] chemoreceptors, proprioceptive receptors in muscles, tendons, and joints and impulses from the cerebral cortex nerves to the intercostals and diaphragmatic muscles. Therefore repeated periodic respiratory exercises help in maintaining the strength, endurance of respiratory muscles and so good ventilation. Normal gas exchange occurs if inspired gas is transmitted through structurally sound, unobstructed air ways to patent, adequately perfused alveoli ${ }^{(22)}$.

Results of group (II) showed highly significant improvement in FVC, FEV1, and MVV with improved percentages of 8 , 18.8 and $12.5 \%$ post training by incentive spirometer respectively. Also there is a significant improvement in FVC, FEV1 and MVV in comparison with the exercise group after two months from training by incentive spirometer with improved percentages of $4.9,8.9$ and $5 \%$ respectively. These results were supported by a previous study which claimed that incentive spirometer is the most effective respiratory muscle training ${ }^{(26)}$. There is a consideration that incentive spirometer is a feed back system to encourage patient for taking deep breath and produce a sustained maximal inspiration for opening and stabilization atelactic areas of lungs ${ }^{(20)}$.

Also a study examined the efficacy of supervised incentive spirometric training program in management of 
pulmonary complications after cardiac valve replacement operations. Twenty patient were treated with routine chest physical therapy program. The other twenty patients were treated with routine chest physical therapy program in addition to incentive spirometer training program. Post operative pulmonary complications were reduced in both groups and there was a significant difference between two groups on pulmonary functions except FEV1/FVC show no significant difference between two groups ${ }^{(27)}$.

In group (III), there was a highly significant improvement in FVC, FEV1, and MVV post training with improved percentages of $9.2,19.5$ and $14.8 \%$ respectively. The results of ventilatory functions showed significant improvement after the training program .These results consistent with the outcome of the research that showed a significant improvement in ventilatory function tests after six weeks of physical training in the form of diaphragmatic breathing exercises, incentive spirometric exercise, gait training, upper limb exercise associated with respiration $^{(28)}$. In comparing the results of group (III) with group (I) after training, there is a significant improvement in favor of group (III) regarding FVC,FEV1and
MVV with improved percentages of 5.9,9.5 and $6.9 \%$ respectively.

However, in comparing the results of group (III) with group (II) after training there was no significant improvement regarding FVC, FEV1, MVV with increased percentages of $0.9,0.5$ and 1.2 respectively. It was proved that the ventilatory functions could be better due to deep breathing exercise or incentive spirometer or both but the best results have been got by incentive spirometer and respiratory muscular exercise ${ }^{(29)}$. On the contrary Crow and Bradeley 1997 stated that addition of incentive spirometer to post operative pulmonary physical therapy is more effective than physical therapy alone $^{(30)}$.

\section{References}

1-Antonini J. M., Taylor, Zimmer A. T. a Roberts J. R. (2004):Pulmonary responses to welding fume: Role of metal constituents. J Toxicol Environ Health A.: 13:67(3): 233-49.

2-Lillienberg L., Zock J. P., Kromhout H., Plana E., Jarvis D., and Toren K. (2007): A population based study on welding exposure at work and respiratory symptoms. Ann Occup Hyg. 4(1):816

3-Ritta E. P., Tania S. S. and Soocheng D. F.(1999):Two years follow up of pulmonary function values among welders in newzeland. Occup. Environ. Med; 56:328-333 
4-Toshio N. (1998):Change in Pulmonary functions as a result of cumulative exposure to welding fumes, occupational function. Med., 55:673-677.

5-Lisa M.B, David F. and Tant S.(1998):Chronic bronchitis related respiratory symptoms and pulmonary function in welders in new Zealand Occup. Environ. 55:150-15.

6-Fidan F., Unlii M., Koknen T., Tetik L., Akgun S. and Demirel (2005): Oxidant- antioxidant status and pulmonary function in welding workers. 47(7) : 286-92.

7-Fishwick D., Bradshaw L., Slater T., Curren A. and Pearce N. (2004): Respiratory symptoms and lung function change in welders: are they associated with workplace exposures. NZ Med J.7;(1193): u872.

8-Halatek T., Sinezuk-Walczak H. and Rydzynski K. (2007): Early neurotoxic effects of inhalation exposure to aluminum and/or manganese assessed by serum levels of phospholipid-binding clara cells protein. J Environ Sci Health A Tox Hazard Subst Environ Eng. 43(2): 118-24.

9-Bowler R. M., Roels H. A., Nakagawa S., Drezgic M. and Diamond E. (2007): Dose- effect relationships between manganese exposure and neurological, neurophysiological and pulmonary function in confined space bridge welders. Occup Environ Med.64(3): 167-77.

10- Luo J. C, Kuo H. W. and Cheng T. J. (2003): Pulmonary function abnormality and respiratory tract irritation symptoms in epichlorohydrinexposed workers in Taiwan. Am J Ind. 43 (4): 440-6.
11- Ralph J. H., Petra J. E., Cecile R. L. and Hans T. M. (2006): Exercise performance improves in patients with COPD due to respiratory muscle endurance training. 129:886-892.

12-Garrod R., Lasserson T. (2007): Role of physiotherapy in the management of chronic lung diseases: an overview of systematic reviews. Respir. Med. 101(12): 2429-36.

13-Larash T., Konishi A., and Suwa, (1994): The effect of incentive spirometry on pulmonary function. Masui. 43(5): 770-3.

14-Racette B.A. and Morelein S. M. (2001): Weldingrelated parkinsonism clinical features, treatment and path physiology. Neurology. 65:8-13.

15-Luo J. C., Hsu K. H. and Shen W. S. (2006): Pulmonary function abnormalities and airway irritation of metal fumes exposure on automobile spot welders. Am J Ind Med. 49(6):40

16-Meo S. A., Azeem M. A., and Subban M. M.( 2003):Lung function in Pakistani welding workers. J. Occup. Environ Med 45(10):106873.

17-El Zein M., Malo J. L .,In Fante. Rivard C. and Gautrink D.(2003):Incidence of probable occupational asthma and changes in airway caliber and responsiveness in apprentices' welders. Eur. Respir. J.;22(3):513-8

18-Ali A.T., BadrN. M., Batanony M. M. and Seri, Z.M.H., (2002): Ventilatory functions response to respiratory exercise program in workers of Tourah Cement Factory. A doctoral thesis, Faculty of physical therapy, Cairo University. P.168 
19-Guyton A. and Hall J. E. (1996): Text book of medical physiology $9^{\text {th }}$ ed (pulmonary ventilation and pulmonary circulation), Ch5 Philadelphia, W.B. Saunders Company.pp.300-318.

20-Delket K., David A. and kervy R.,(1994):The effect of biofeed back assisted breathing retraining in lung function in patient with cystic fibrosis.Chest.100:23-28.

21-Amawy A. A., Emara A. M. and Ibrahim A.(1982):Effect of physical therapy on workers with chronic obstructive lung disease in jute and hemf industry. A Master Thesis, Faculty of Physical therapy, Cairo University.P140

22-Merk, (2001):pulmonary disorder \& pulmonary function testing, white house state in USA. The Merck manual of diagnosis and therapy J.;20(5):4-7.

23-Spengler C. M., Lenzin C., Stussi C. and Mrkov (1998):Decreased perceived respiratory exertion during exercise after respiratory endurance training.Am.J. Respir.Crit.Care Med.;157:7823788.

24-Sayed A. A., Badr N. M. and El Maghraby M. A., (1996):Effect of breathing exercises on pulmonary function in insecticides spray workers. A master thesis, Faculty of Physical Therapy, Cairo University, p60.

25-Jadrank S., Michel D., and Alejandro G. (2005):Effects of imposed pursed lips breathing on respiratory mechanics and dyspnea at rest and during exercise in COPD. Chest. 128:640-50.

26-Scherer T. A., Spengler C.M., Owassapain D., Imbhaf E. and Boutellier U.(2000):Respiratory muscle endurance training in chronic obstructive pulmonary disease impact on exercise capacity, and quality life. An. J. Respir. Crit. Care. Med.162(5):1709-14

27-Mokhtar Y. E., Nossier A. H. and Abdel Ghany A. M. (2003):Evaluation of supervised Incentive spirometry training regime in the management of pulmonary complications after valvular operation. A master thesis, Faculty of Physical Therapy, Cairo University.pp98-102.

28-Mahmoud, M. M., RAHMY A. F., Sultan I. E. and Seri Z. M. H. ( 2002):Efficacy of physical training on ventilatory functions in Alzheimer's A master, Faculty of Physical Therapy, Cairo University. P906.

29-Abrons H. L., Peterson M. R., Sanderson W. T., Engelberg A. L. and Harber P. (1999): Symptoms, Ventilatory functions and environmental exposure in portald cement workers. Br.J. In. Med. 45(10): 720.

30-Crow J. M. and Bradeley C. A. (1997): “The Effectiveness of incentive Spirometer with Physical therapy for High- risk patient after coronary artery by pass surgery. Physical Therapy. 77(3):260-8. 